\title{
Research Upon Construction of Technology-applied Laboratory*
}

\author{
Guanqiang Ruan \\ School of Automobile, Shanghai Dianji University, Shanghai, China \\ ruangq@sdju.edu.cn
}

\begin{abstract}
It is extensively recognized by domestic institutions of higher learning that newly-established undergraduate colleges orientate themselves towards focusing on training technology-applied professionals. However, the construction of technology-applied undergraduate laboratory is still in the preliminary stages of exploration. The success of the laboratory construction has a lot to do with the implementation of Technology-applied undergraduate education strategy. From the concept and ideas of laboratory construction, experimental methods and means, lab teaching staff construction, for the technology applied undergraduate laboratory construction, a preliminary exploration is made in this article.
\end{abstract}

Index Terms - Technical application, Construction of laboratory, Exploration

\section{Introduction}

Technology-applied undergraduate education is the origin and important phase for cultivating high-quality technical personnel, one of the most important parts is the practice teaching, experimental teaching is an important part of the whole process of teaching practice, and the laboratory construction is inseparable with the quality of experimental teaching. Now in the technology-applied undergraduate colleges and universities, a consensus had been reached for the technology-applied system and mode, but for the laboratory construction and management, very little nearly no research had been done. numerous technology-applied in the colleges and universities indiscriminately imitated the management mode of laboratory construction of the research or research teaching universities and colleges of undergraduate, especially the newly upgraded undergraduate colleges and universities, they followed the management mode of others in addition, also with residual old college or technical secondary school pattern of laboratory construction. Based on the practice of laboratory construction in Shanghai Dianji University, an innovation of laboratory construction mode is discussed for the technology-applied undergraduate colleges and universities.

\section{The Orientation of Technology-applied Personnel Training Objective}

Laboratory construction is in the service of the personnel training objective, to the build technology-applied laboratory of colleges and universities, the orientation of technology-applied personnel training objective should be made clear. The objective of Technology-applied undergraduate colleges is to cultivate advanced technical personnel with strong technological foundation, practical skills and applied ability and in the service of production, construction, management and front line. These kind of advanced technical personnel usually can plan to realize technical development progress after engineering development, provide technical guarantee and support, and finally complete the technical task in the process of application. They are carriers, perpetrators and implementers of modern technology. The construction of laboratory can be very well for the implementation of undergraduate talents cultivation orientation, only according to the orientation of technology-applied personnel training objective [1].

\section{Problems in the Technology-applied Laboratory Construction}

There are two misunderstandings in the target of the laboratory construction in the application-oriented undergraduate colleges and universities: one is unrealistically imitating the laboratory construction in research universities, the other one is following the laboratory construction mode of the vocational colleges. The former causes a strong academic atmosphere, the students in technology-applied undergraduate colleges are relatively poor in basic knowledge, and the students complain incapability, worse mastery of theory and poor operational ability; while the latter one leads to a worse mastery of theoretical foundation, poor innovation ability and no subsequent potential in enterprises. Therefore, "it is to struggling to calculate the extravert, compound and applied type talents with adaptive capacity and competitive ability under socialist market economy, in the premise of insisting on broad caliber, thick foundation and high quality, with the orientation of market demand, the foundation of general education, and the standard of ability training" [2]. Pan Maoyuan and Che Rushan thought, technology-applied undergraduate talents are different from the skilled talents cultivated in higher vocational college, as well as from traditional academic talents of undergraduate course colleges and universities. Traditional undergraduate colleges and universities cultivated research and academic talents of generous basic knowledge and high comprehensive quality, and with good self-learning ability. Skilled talents trained in higher vocational college is geared to the needs of production, service, construction and management of first line technology, their update ability of professional knowledge and

\footnotetext{
* This work is supported by fund project of Shanghai Dianji University (Project No. 2013JYJG-07 and No. 12XKJC02).
} 
comprehensive quality are relatively weaker. Applied university is to adapt to the social need of applied talents, their knowledge, ability and quality structure have distinctive characteristics, and have theoretical foundation, wide professional knowledge, strong practical ability, high comprehensive quality, such as the strong ability of science and technology, promotion, transformation [3]. Xia Jianguo argues that technology undergraduate talents training target must achieve the demands in two aspects: the one is to reach the standard of education of the higher education undergraduate level, the other one is to cultivate the talents that should be applied, having strong ability of technical practices. Specifically, is to "develop senior technical personnel with a strong theoretical basis, practical skills and application ability and in the service of production, construction, management of the first line (also called 'technician' or 'technical engineers')".Thus, the researchers thought that technology undergraduate talents training target, compared with the ordinary undergraduate course major, is to cultivate technology applied talents. Relative to the higher vocational college, it requires that the students have more generous theoretical basis and certain innovation ability [4].

\section{Discussions of Technology-applied Laboratory Construction}

\section{A. Innovation idea of technology-applied laboratory construction}

The laboratory construction should be based on students, have passing on knowledge, ability cultivation, quality improvement as the education idea and ability training as the core concept of laboratory construction. It should be to set up experimental teaching system to cultivate students' practice ability and innovation ability, construct experimental teaching team of good quality teaching for meeting the needs of the modern experiment, construct resource sharing, open service experiment teaching environment with advanced instrument and equipment, establish a modern efficient management mechanism to improve the experimental teaching level. Laboratory should be to foster students' practical ability, innovation ability and improve the quality of teaching as the purpose, the reform of experiment teaching as the core, based on the resources sharing of the open experiment, the high quality experiment teaching team and perfect experimental conditions for guarantee, innovate management mechanism, comprehensively improve the level of experimental teaching and laboratory. Since the network is developed, a lot of knowledge can be got from the Internet, students in experiment classes, especially some classic or old experiments, which are already difficult to interest the students, it puts forward some new problems on the laboratory construction, such as how to construct and update experimental equipment in the laboratory, considering introducing multimedia and network technology, for some traditional experimental project to carry on the revolutionary innovation.

\section{B. Discussion on technology-applied experimental methods and means of construction innovation}

Popularization of higher education, implementation of quality education, it has pay attention to train high quality applied talents for social needs. It needs to broaden the basis of education, reform the teaching contents, teaching methods and teaching means in course education. As the science and technology develop, while its marked characteristic is highly integration based on the highly differentiation, it demands the crossing and infiltrating mutually various disciplines, and constantly opens up new research fields. For fostering talents in higher education, knowledge, ability and quality need organically blend into an organic whole. So it should emphasize the majors and strengthen discipline construction and the cultivation of students' ability and strengthen the cultivation of comprehensive application ability and exercise. The laboratory under the existing system is set up as the subjects, and the subject is single, the experimental curriculum is very independent, lack of fusion between disciplines cross and penetration. Ready experiments get ready first by the experimental teachers, students are just to verificate the experiments in laboratory, experiment content is only around this course setting, this make students be dependency, lack of independence, it is not conducive to cultivate students roundly and systematically scientific experiment ability, comprehensive ability and innovation ability, affect the quality of the talents cultivation [5].

Teachers should instruct students' experimental basic theory and knowledge; principle of experimental technology, error theory and data processing methods, scientific research method, literature review, the writing methods of scientific papers and technical reports in the form of lecture, students self-training mainly is the core of the experimental teaching. For skill training and basic experiment, students can use the computer simulation experiment on the basis of preview of lab handouts, and then each student practices independently in the laboratory measurements, and writes test report after class. For the comprehensive and designing type and innovative experiment, 2-3 people form a group, under the guidance of teachers, starting from the experimental background, study related theory knowledge, students have to complete the literature experiment plan, design, assembly and debugging instrument, measurement data, data analysis, and discussing the results, and finally write a scientific paper format report, and participate in "open and research" communicating meeting. Through a variety of teaching forms of practice training above, the students not only master experiment skill and technology, but also learn to ask questions, scientific methods to analyze and solve problems, develop thinking, familiar with and experience research process, this make students of the scientific thinking, with scientific spirit, improve their comprehensive quality.

\section{C. technology applied innovation laboratory team construction}

With the development of teaching and scientific research work and the deepening of the reform, the laboratory teaching 
team construction in colleges and universities become a prominent problem. Laboratory personnel responsibility is uncertain, because most of the teachers do not assume the experiment teaching tasks, the lab technician is responsible for the experiment preparation, experiment teaching, and lab daily management work and so on. This causes that high level personnel are reluctant to undertake the low-level work, low level workers cannot be competent on high level of work, and it results in the deteriorating of the quality of work, especially this kind of phenomenon rises in the new undergraduate course colleges and universities. Lab technician is the main undertaker of the experimental teaching work; make a great contribution for the teaching and scientific research work. But due to the position of experimenter post is not clear in the university, the lack of reasonable evaluation mechanism, it cause the experimenter to undertake large and heavy work for a long time, without due approval, this will discourage experimenter, influence the stability of laboratory technician team, hinder the practice teaching work smoothly. Laboratory team is weak, this is for many years due to ignoring laboratory team construction in colleges and universities [6] [7].

Vice-chancellor of Beijing institute of technology university, Sun Fengchun believes that in the laboratory team including teaching, management, technical support team, must be given attention. For status, treatment, laboratory team should develop a series of policy for guarantee. In teaching jobs total amount control, structural adjustment, strengthen management, improve quality, under the principle of treatment, improved laboratory backbone teachers should vigorously promote on-demand positioned, according to the post employment reform. Beijing institute of technology has appointed a batch of lab director, the lab director responsibility system, has a clear lab director. And regulate that the position of the director of basic course teaching laboratory personnel enjoy a higher post allowance than that of the same title personnel [8].

For technology-applied undergraduate education, the stability of the laboratory team is particularly important. It need to improve the laboratory team wages, this is the key issues of the laboratory team construction, and also the question begged by a lot of leaders. To do well in technology-applied undergraduate education, the problem must be solved, to effectively implement localization of the undergraduate course school. As the proposal of Sun Fengchun, who is vice President of Beijing Institute of Technology, it is a good way. Good actually improving lab director treatment alone is not enough, it is essential to improve all the first-line experimental teachers' treatment, so that everyone has an idea of working in laboratory, then the laboratory team construction problems will be readily solved.

\section{Conclusions}

Along with the development of science, the expansion of education scale, the construction pattern of the current technology-applied undergraduate experiment has not changed or optimized, and has failed to keep pace with the requirements of the popularization of higher education increasingly. This article from three aspects of the concept and ideas of laboratory construction, experimental teaching method construction, laboratory team construction, has carried on the preliminary discussion on construction technology-applied undergraduate laboratory, and puts forward the corresponding solutions, and it would provide some references for technology-applied undergraduate laboratory construction.

\section{References}

[1] Xia Jianguo. Introduction to technical undergraduate education. Shanghai: the Orient publishing center, 2007:130.

[2] zhang Lin, TaoJunCheng, ms. Applied undergraduate talents training target and talent training model innovation study. Journal of today's garden, 2006, 9.

[3] Pan Mao yuan, CheRuShan. Zhao xuegang. Some discussions on the orientation of applied undergraduate colleges. Journal of higher education research, 2009, 5.

[4] Xia Jianguo. Based on the theory of classification of talent review the talents training goal of technical undergraduate education. Journal of higher education research, 2007, 5.

[5] Tan Xiaocui, seam silver, MAO Zhang Li. Strengthen the laboratory opening management, promote the effective utilization of resources. Journal of experimental science and technology, 2010, 8 (6): 77-78176.

[6] frisby, Xiong Xiaotao Xue Rundong, Sun Jiancai. How to do a good job of laboratory in colleges and universities in the new period preliminary study. China's Foreign Trade, 2010, (10): 232.

[7] Zhang Shuangcai Wang Youming, Luo Lian club. To optimize the structure to perfect the mechanism of building high-quality experiment technology team. Journal of laboratory research and exploration, 2007, 26 (6): 116-118.

[8] Sun Fengchun. Play to the role of the laboratory management department to improve laboratory status. Journal of laboratory research and exploration, 2006, 25 (5): 545-546. 